\title{
Professional and psychosocial factors affecting the intention to retire of Australian medical practitioners
}

\author{
Chanaka Wijeratne ${ }^{7}$, Joanne K Earl ${ }^{2}$, Carmelle Peisah ${ }^{3}$, Georgina M Luscombe ${ }^{4}$, Johanna Tibbertsma ${ }^{3}$
}

The known The number of doctors who work beyond the age of 65 is growing. Studies of retirement intention have focused on single factors, such as health and income, and have generally been limited to single specialties.

The new $38 \%$ of doctors aged 55 or more were unsure about retiring or did not intend to retire. Both professional and broader psychosocial factors (including financial resources, work centrality, emotional resources, anxiety about ageing) influenced the intention to retire.

The implications Education programs facilitating retirement planning are needed for late career doctors, including advice on financial planning and developing non-professional interests.

I $\mathrm{n}$ the absence of a mandatory retirement age in Australia, many doctors work beyond the age of $65 .{ }^{1}$ In $2014,9.9 \%$ of the medical workforce were 65 or older, and the total number of doctors over 65 years of age has increased by $80 \%$ since $2004,{ }^{1,2}$ consistent with an ageing society.

Older practitioners who prolong their careers are important for providing medical care as well as for teaching and mentoring younger colleagues. ${ }^{3}$ These benefits, however, must be weighed against a complex array of factors associated with ageing, including physical and cognitive changes that may hinder optimal practice. ${ }^{4}$

The challenges associated with retiring from a career in medicine were highlighted by the finding that only $61 \%$ of older Australian psychiatrists had commenced planning their retirement. ${ }^{5}$ Anticipated reasons for retirement reported in single specialty studies include deteriorating health and family or personal reasons; ${ }^{5}$ self-perception of one's skill levels, rather than age; $;^{6}$ and financial aspects and the inability to find a suitable replacement.

Whether the broader retirement literature is directly applicable to the medical profession is unclear. ${ }^{8}$ The largest reported effect sizes for factors favouring retirement planning have been for work involvement and job satisfaction. We similarly suggest that being a doctor is so closely linked with self-identity ${ }^{9}$ as to make retirement threatening. If so, it would be expected that work centrality - the extent to which work is of primary personal importance compared with other life roles; that is, an indicator of a person's affective commitment to work ${ }^{10}$ — would be higher in doctors who are less inclined to retire. Further support for this hypothesis would be that doctors are less likely to retire if work is perceived as a calling (the work itself is fulfilling and perceived as contributing to the greater good), rather than a career (achievement is defined by advancement and promotion) or job (defined purely by financial success). ${ }^{11}$

Other psychological factors that may affect retirement planning include positive emotions, such as adaptability and optimism.
Abstract

Objective: To determine the professional and personal factors associated with the intention to retire (ITR) by medical practitioners.

Design, participants and setting: Cross-sectional survey of currently practising Australian doctors aged 55 or older registered with a commercial database. Participants completed an online self-report questionnaire in October 2015.

Main outcome measures: Associations between intention to retire and demographic and practice characteristics; health; emotional, social and financial resources; work centrality; and anxiety about ageing.

Results: $62.0 \%$ of 1048 respondents (17.5\% response rate) intended to retire, $11.4 \%$ had no intention of retiring and $26.6 \%$ were unsure. The odds of retiring were higher for those with adequate financial resources (adjusted odds ratio [aOR], 1.31; 95\% Cl, 1.18-1.44) and greater anxiety about ageing (aOR, 1.05; $95 \% \mathrm{Cl}, 1.02-1.09$ ); the odds of retiring were lower for international medical graduates (aOR, 0.61; 95\% Cl, 0.44-0.85), for those with greater work centrality (aOR, 0.89; $95 \% \mathrm{Cl}, 0.85-$ 0.92 ) and greater emotional resources (aOR, 0.96; $95 \% \mathrm{Cl}$,

0.93-0.98). In a model including medical specialty as a variable, being a psychiatrist (aOR, 0.40; 95\% Cl, 0.20-0.79) or general practitioner (aOR, $0.54 ; 95 \% \mathrm{Cl}, 0.34-0.87$ ) were associated with reduced odds of intending to retire.

Conclusion: Intention to retire was determined by a mixture of professional and psychosocial characteristics. In particular, our results support the view that delaying retirement by doctors may be related to the primacy of work compared with other life roles. Our results may be used to develop educational programs that support the transition to and improve adjustment to retirement.

Anxiety about ageing - the tendency to fear anticipated threats and losses associated with advancing age $\mathrm{e}^{12}-$ may also be involved.

The factors that are weighed when considering retirement have not been explored in specific subgroups of doctors, such as international medical graduates (IMGs). Working in a rural or remote area may hinder retirement planning, given the lower replacement rates in such locations.

The aim of our survey was to determine the professional and personal factors associated with the intention to retire (ITR) among older medical practitioners. Significant correlations between retirement intention and subsequent retirement behaviour have been reported in the general literature on retirement. ${ }^{13}$

\section{Methods}

We undertook a cross-sectional self-report survey of doctors aged 55 or more, using a commercial database rented from the 
Australasian Medical Publishing Company (AMPCo). A pilot study (among doctors in the Australian Capital Territory and South Australia) verified the questionnaire items and data collection methodology. The main study was conducted in October 2015: 6000 doctors received an email from AMPCo (independently of the study authors) with an embedded link to the survey, twice within 2 weeks. Participants were offered the chance to win one of ten $\$ 50$ gift vouchers. Data from the pilot study were not included in the data analysed in this article.

\section{Questionnaire}

The questionnaire (see online Appendix) included questions about demographic and professional details, such as country in which the primary medical degree was obtained, specialty, geographic location, and hours and type of practice. Representative items from the social resources and financial resources subscales of the Retirement Resources Inventory (RRI) ${ }^{14}$ were included. Health was measured on a 5-point self-rating scale of overall physical health, and also with the Self-Administered Comorbidity Questionnaire (SACQ) ${ }^{15}$ which asked whether the participant experienced, received treatment for, or was limited by any of 12 common medical problems.

Psychological variables were assessed with the K10, a validated screening instrument for measuring psychological distress. ${ }^{16}$ Items from the emotional resources subscale of the RRI that measure positive emotion, mastery, self-esteem, and self-perception of cognitive functioning ${ }^{14}$ were applied. The Anxiety about Ageing Scale $^{17}$ was administered, including items reflecting each of four previously validated dimensions: fear of old people, psychological worries, concerns about physical appearance, and fear of losses.

A doctor's self-identification with medical practice was assessed by two methods. The Work Centrality Questionnaire measures the primacy of work in a person's life. ${ }^{18}$ Participants were also asked to state (on a 7-point Likert scale, ranging from "strongly agree" to "strongly disagree") whether they viewed medical practice as a "job," a "career", or a "calling".

Participants were asked to indicate whether they intended to retire (options: "I do not intend to retire"; "I do not know whether I will retire"; "I do intend to retire"). Those who intended to retire were asked to indicate a retirement age, and to rate the salience of factors that would determine its timing (on a Likert scale). Similarly, those who did not plan to retire or were unsure were asked about factors determining their decision. These factors were derived from previous research on older doctors, and from the general literature on retirement. ${ }^{19,20}$

\section{Statistical analyses}

As there was significant skew in the distribution of continuous variables (determined in one-sample Kolmogorov-Smirnov tests), descriptive statistics are reported as medians and interquartile ranges (IQRs). For categorical and dichotomous variables, numbers and percentages are reported. Skewed continuous data for dichotomous groupings were compared in Mann-Whitney $U$ tests; $\chi^{2}$ tests and linear-by-linear association tests for ordinal variables were applied in univariate analyses of variables with respect to age, sex and ITR. Please note when interpreting results that it is possible for groups to have different rank sums that are statistically significant in non-parametric tests, but to also have identical or nearly identical medians.

Potential predictors with a significant relationship with ITR (univariate analysis, $P<0.2$ ) were included in logistic regression models, with dichotomised ITR as the dependent variable. The first model included all participants, the second and third models assessed each age group separately (55-64 years, 65 years and over), and the fourth and fifth models each sex. A sixth model included medical specialties for which there were at least 50 respondents.

A two-block variable entry procedure was applied; block 1 included demographic factors (age, sex, location of practice, country of qualification), with forced entry. In block 2, forward conditional likelihood ratio entry was used for survey scores.

All analyses were conducted in SPSS 22 (IBM). $P<0.05$ was deemed statistically significant.

\section{Ethics approval}

The study was approved by the Human Research Ethics Advisory Panel of the University of New South Wales (reference, 2014-7-68).

\section{Results}

Of the 6000 doctors invited to participate, 1049 responded; one participant was excluded because they had recently retired, leaving a final cohort of 1048 (response rate, 17.5\%). The proportion of respondents by state and territory was similar to the proportion of registrants aged 55 and older located in the respective jurisdictions: ${ }^{1} 37.1 \%$ from New South Wales, 26.2\% from Victoria, 20.7\% from Queensland, 11.6\% from Western Australia, 2.6\% from Tasmania, and $1.2 \%$ from Northern Territory; five respondents $(0.5 \%)$ were from the ACT and SA.

The demographic characteristics of the participants are summarised in Box 1 . The median age was 65 years (IQR, 59-69 years; range, 55-89 years). The medical specialties with at least 50 respondents were general practice (439 doctors, $41.9 \%$ of sample), internal medicine specialists $(122,11.6 \%)$, anaesthesia $(72,6.9 \%)$, surgery $(71,6.8 \%)$ and psychiatry $(56,5.3 \%)$. Compared with national data, the sample was similar with regard to the proportion of female doctors aged 55 or more and general practitioners aged 55 or more, but there were fewer IMGs.

Six hundred and fifty respondents $(62.0 \%)$ intended to retire; the others (combined as one group in further analyses) either had no intention of retiring $(11.4 \%)$ or were unsure $(26.6 \%)$. There were no differences in ITR according to age or sex (Box 2). There were, however, statistically significant differences between the five specialties with more than 50 respondents $(P=0.001)$ : anaesthetists were the most likely to affirm an ITR $(76 \%)$, followed by surgeons (69\%), internal medicine specialists (67\%), GPs (56\%), and psychiatrists $(50 \%)$.

Of the doctors who intended to retire, 33\% did not nominate a specific retirement age. The anticipated retirement age for those who did increased progressively with age: for those aged 55-64 years, the median anticipated retirement age was 65 years (IQR, 65-68 years); for those aged 65-74, it was 71 years (IQR, 70-75 years); for those aged 75-84, it was 80 years (IQR, 78-83 years); and for those aged 85 or more, it was 86 years (IQR, $86-88$ years). The median anticipated retirement age was 70 years (IQR, 65-73 years) for men and 68 years (IQR, 65-71 years) for women.

There were significant differences by age in the anticipated reasons for retirement. Those aged 55-64 years were more likely than older doctors to nominate achieving financial security, being able to access superannuation, a desire for more personal or leisure time, and a partner or spouse retiring. Further, the younger group was more likely to plan transition to retirement by reducing working hours. Women were more likely to nominate a partner retiring as an anticipated reason for retirement (Box 2). 


\begin{tabular}{|c|c|c|c|c|c|c|c|}
\hline & Total & 55-64 years old & 65 years old or more & $P$ & Men & Women & $P$ \\
\hline Number of doctors & 1048 & $520(49.6 \%)$ & $528(50.4 \%)$ & & $807(77.0 \%)$ & $241(23.0 \%)$ & \\
\hline Married (de jure/de facto) & $921(87.9 \%)$ & $458(88.1 \%)$ & $463(87.7 \%)$ & 0.85 & $745(92.3 \%)$ & $176(73.0 \%)$ & $<0.001$ \\
\hline Work less than $40 \mathrm{~h} /$ week & $558(53.2 \%)$ & 206 (39.6\%) & $352(66.7 \%)$ & $<0.001$ & 403 (49.9\%) & 155 (64.3\%) & $<0.001$ \\
\hline International medical graduate & $205(19.6 \%)$ & $75(14.4 \%)$ & $130(24.6 \%)$ & $<0.001$ & $157(19.5 \%)$ & $48(19.9 \%)$ & 0.87 \\
\hline Live in a capital city & $646(61.6 \%)$ & $317(61.0 \%)$ & $329(62.3 \%)$ & 0.77 & $491(60.8 \%)$ & $155(64.3 \%)$ & 0.33 \\
\hline Solo practitioner* & $197(19.9 \%)$ & $74(14.8 \%)$ & $123(25.0 \%)$ & $<0.001$ & $154(20.1 \%)$ & $43(18.9 \%)$ & 0.69 \\
\hline \multicolumn{8}{|l|}{ Self-rated health } \\
\hline Excellent/very good & $718(68.5 \%)$ & $355(68.3 \%)$ & $363(68.8 \%)$ & 0.87 & $546(67.7 \%)$ & $172(71.4 \%)$ & 0.28 \\
\hline Poor to good & $330(31.5 \%)$ & $165(31.7 \%)$ & $165(31.3 \%)$ & & $261(32.3 \%)$ & $69(28.6 \%)$ & \\
\hline SACQ score, median (IQR) & $2.0(0.0-4.0)$ & $2.0(0.0-3.0)$ & $2.0(1.0-4.0)$ & $<0.001$ & $2.0(0.0-4.0)$ & $2.0(0.0-3.0)$ & 0.031 \\
\hline K10 score, median (IQR) & $12.0(11.0-15.0)$ & $13.0(11.0-15.0)$ & $12.0(11.0-14.0)$ & $<0.001$ & $12.0(11.0-15.0)$ & $12.0(11.0-15.0)$ & 0.68 \\
\hline \multicolumn{8}{|l|}{ Perception of work } \\
\hline Job & $59(5.6 \%)$ & $37(7.1 \%)$ & $22(4.2 \%)$ & 0.11 & $49(6.1 \%)$ & $10(4.1 \%)$ & 0.013 \\
\hline Career & $423(40.4 \%)$ & $203(39.0 \%)$ & $220(41.7 \%)$ & & $342(42.4 \%)$ & $81(33.6 \%)$ & \\
\hline Calling & $566(54.0 \%)$ & $280(53.8 \%)$ & $286(54.2 \%)$ & & $416(51.5 \%)$ & $150(62.2 \%)$ & \\
\hline $\begin{array}{l}\text { Work centrality score, } \\
\text { median (IQR) }\end{array}$ & $23.0(21.0-25.0)$ & $23.0(20.0-25.0)$ & $23.0(21.0-25.0)$ & 0.001 & $23.0(21.0-25.0)$ & $23.0(20.0-25.0)$ & 0.16 \\
\hline $\begin{array}{l}\text { Anxiety about ageing score, } \\
\text { median (IQR) }\end{array}$ & $29.0(26.0-32.0)$ & $29.0(25.0-32.0)$ & $29.0(26.0-32.0)$ & 0.24 & $29.0(26.0-32.0)$ & $30.0(25.0-32.0)$ & 0.48 \\
\hline
\end{tabular}

Among doctors who did not intend to retire or were unsure about retirement, there were significant differences by age in the reasons for continuing to work. Doctors aged 65 or older were more likely to indicate that continuing to work was motivated by the wishes of their partner or family, the cognitive stimulation afforded by work, their maintaining a sense of purpose, or their good physical health. Men were more likely to nominate a partner's or family's wishes as a reason for continuing to work (Box 3).

\section{Factors associated with intention to retire}

For the entire sample of respondents, the odds of ITR were lower for IMGs, and for those with a higher work centrality score and greater emotional resources. The odds of ITR were higher for doctors with better financial resources and greater anxiety about ageing (Box 4, model 1). It is notable that factors such as location of practice, social resources, and objective health were not significant factors.

For doctors aged 55-64 years, the odds of ITR were higher for those with better financial and social resources, and lower for IMGs and for those with greater work centrality. For doctors aged 65 or more, the odds of ITR were higher for doctors with better financial resources and greater anxiety about ageing, and lower for those with greater work centrality and greater emotional resources (Box 4, models 2 and 3).

\section{Factors determining the timing of retirement among 650 doctors who intend to retire}

\begin{tabular}{|c|c|c|c|c|c|c|c|}
\hline & Total & $55-64$ years old & 65 years old or more & $P$ & Men & Women & $P$ \\
\hline $\begin{array}{l}\text { Intend to retire (proportion of } 1048 \\
\text { respondents) }\end{array}$ & $650(62.0 \%)$ & 335 (64.4\%) & $315(59.7 \%)$ & 0.11 & 497 (61.6\%) & $153(63.5 \%)$ & 0.59 \\
\hline Intend to transition to retirement & $540(83.1 \%)$ & $296(88.4 \%)$ & $244(77.5 \%)$ & $<0.001$ & $416(83.7 \%)$ & $124(81.0 \%)$ & 0.44 \\
\hline \multicolumn{8}{|l|}{ Factors affecting timing of retirement* } \\
\hline Financial security & $371(57.1 \%)$ & $220(65.7 \%)$ & $151(47.9 \%)$ & $<0.001$ & $294(59.2 \%)$ & $77(50.3 \%)$ & 0.054 \\
\hline Physical illness/disability & $364(56.0 \%)$ & $190(56.7 \%)$ & $174(55.2 \%)$ & 0.70 & $275(55.3 \%)$ & $89(58.2 \%)$ & 0.54 \\
\hline Cognitive impairment & $354(54.5 \%)$ & $177(52.8 \%)$ & $177(56.2 \%)$ & 0.39 & $272(54.7 \%)$ & $82(53.6 \%)$ & 0.81 \\
\hline Work-related burnout & $255(39.2 \%)$ & $141(42.1 \%)$ & $114(36.2 \%)$ & 0.12 & $192(38.6 \%)$ & $63(41.2 \%)$ & 0.57 \\
\hline Act as carer & $178(27.4 \%)$ & $92(27.5 \%)$ & $86(27.3 \%)$ & 0.96 & $127(25.6 \%)$ & $51(33.3 \%)$ & 0.06 \\
\hline Desire more personal/leisure time & $438(67.4 \%)$ & $243(72.5 \%)$ & $195(61.9 \%)$ & 0.004 & $336(67.6 \%)$ & $102(66.7 \%)$ & 0.83 \\
\hline Ability to access superannuation & $225(34.6 \%)$ & $134(40.0 \%)$ & $91(28.9 \%)$ & 0.003 & $178(35.8 \%)$ & $47(30.7 \%)$ & 0.25 \\
\hline Spouse/partner retiring & 139 (21.4\%) & $94(28.1 \%)$ & $45(14.3 \%)$ & $<0.001$ & $97(19.5 \%)$ & 42 (27.5\%) & 0.036 \\
\hline
\end{tabular}

* Responses for each factor were dichotomised into "strongly agree"/“agree" $v$ other responses. 
3 Factors determining decision to continue working for 398 doctors not intending to, or unsure about, retirement

\begin{tabular}{|c|c|c|c|c|c|c|c|}
\hline & Total & $55-64$ years old & 65 years old or more & $P$ & Men & Women & $P$ \\
\hline $\begin{array}{l}\text { Do not intend to retire, or unsure (proportion } \\
\text { of entire sample) }\end{array}$ & $398(38.0 \%)$ & $185(35.6 \%)$ & $213(40.3 \%)$ & 0.11 & $310(38.4 \%)$ & $88(36.5 \%)$ & 0.59 \\
\hline \multicolumn{8}{|l|}{ Factors affecting timing of retirement* } \\
\hline Relationship with patients & $232(58.3 \%)$ & $101(54.6 \%)$ & $131(61.5 \%)$ & 0.16 & 179 (57.7\%) & $53(60.2 \%)$ & 0.68 \\
\hline Cognitive stimulation & $349(87.7 \%)$ & $154(83.2 \%)$ & $195(91.5 \%)$ & 0.012 & $273(88.1 \%)$ & $76(86.4 \%)$ & 0.67 \\
\hline Finances & $229(57.5 \%)$ & $115(62.2 \%)$ & $114(53.5 \%)$ & 0.08 & $174(56.1 \%)$ & $55(62.5 \%)$ & 0.29 \\
\hline Fulfilling professional relationships & $254(63.8 \%)$ & $114(61.6 \%)$ & $140(65.7 \%)$ & 0.40 & $196(63.2 \%)$ & $58(65.9 \%)$ & 0.64 \\
\hline Good physical health & $312(78.4 \%)$ & $134(72.4 \%)$ & $178(83.6 \%)$ & 0.007 & $239(77.1 \%)$ & $73(83.0 \%)$ & 0.24 \\
\hline Family's/partner's wishes & $136(34.2 \%)$ & $49(26.5 \%)$ & $87(40.8 \%)$ & 0.003 & $118(38.1 \%)$ & $18(20.5 \%)$ & 0.002 \\
\hline Sense of purpose/goals & 322 (80.9\%) & $140(75.7 \%)$ & 182 (85.4\%) & 0.013 & $248(80.0 \%)$ & $74(84.1 \%)$ & 0.39 \\
\hline
\end{tabular}

The factors significant for ITR in male doctors were the same as for the whole sample. For women, the odds of ITR were higher for doctors with better financial resources, and lower for those with greater work centrality score and greater emotional resources (Box 4, models 4 and 5).

When regression analysis was restricted to doctors from the five specialties with more than 50 respondents (Box 4, model 6), the odds of ITR were lower for doctors who were IMGs, psychiatrists, GPs, and for those who reported greater work centrality and greater emotional resources. The odds of ITR were also higher for doctors with better financial resources and greater anxiety about ageing (Box 4, model 6).

\section{Discussion}

This is the first study of the broader professional and psychosocial factors associated with retirement intention among doctors in different specialties. Planning retirement has benefits for the continuity of patient care and service provision, and is likely to assist the medical practitioner's adjustment to retirement. ${ }^{21}$

Our sample of doctors were less likely to retire than people aged 45 and over in the general population: male doctors planned to retire 4 years later (at age $69.7 v 65.7$ years) and female doctors 3.6 years later (age $68.1 v 64.5$ years) than people in the general community, while fewer doctors reported an ITR (62\% v 79\%). ${ }^{19}$ Only twothirds of doctors who intended to retire nominated a retirement age, and the anticipated age increased progressively with each successive 10-year age bracket.

There were a number of differences between age groups in the reasons for either anticipating retirement or continuing to work. The responses of doctors aged 65 or more who intended to continue to work suggested that this group was financially independent, enjoyed good physical health, and valued a sense of purpose in life more than leisure time.

Women were more likely than men to accompany a spouse into retirement, and a greater proportion of women nominated responsibilities as a carer as a reason for retiring (although the difference was not statistically significant), consistent with data for the general community. ${ }^{19,22}$ Men were more likely to continue working because of the wishes of a partner or family.

Two factors, work centrality and financial resources, consistently predicted ITR in all regression models. It is unclear whether the association of greater work centrality with reduced odds of retiring is related to the self-identity of people attracted to medicine and, if so, whether this effect is limited to the current sample or generally applies to doctors over 55. Alternatively, the nature of medical practice may lead to work becoming the pre-eminent feature of one's life. That greater emotional resources and greater anxiety about ageing were also associated with reduced odds of retirement is another indication of the importance of personal characteristics in determining retirement intentions.

Financial security was the other consistent factor when considering retirement, in keeping with data for the general community. ${ }^{19}$ Retirement intentions were informed by the views of a broader community, not just the practitioner themselves; for one-third of doctors the wishes of partners and family were a key consideration in the decision to keep working.

The desire of IMGs to delay retirement is unsurprising, given their later entry into the medical workforce in Australia. Interpretation of ITR in different specialties was limited by the fact that only five provided sufficient responses for statistical analysis. The odds of GPs and psychiatrists intending to retire were the lowest of the five specialties; this may reflect the respective salience for these two groups of financial rewards and physical demands in decision making about retiring. Although being a surgeon or anaesthetist were not significant factors in regression model 6 , the proportions of respondents in these two specialties who planned to retire was greater than in the other three; this was perhaps related to the systemic approaches to ageing and retirement undertaken by their respective colleges. ${ }^{23}$

There are limitations to our study. These include the modest response rate to our survey of $17.5 \%$. Although comparable with similar surveys, ${ }^{24}$ the low rate limits our ability to generalise our findings about subgroups of doctors. In addition, there are potential sources of bias, such as sample skewing toward doctors who were already contemplating retirement, the lack of demographic data on respondents apart from age, sex, and the proportion of practitioners in a specialty compared with their overall state/ territory proportion, the under-representation of IMGs, and the electronic format of the survey. Although our sample was not fully national, its demographic data were comparable with national data on the proportions of women, GPs, and the states of practice. Finally, the cross-sectional nature of the survey did not allow retirement intention to be analysed as a dynamic process, although significant correlations between retirement intention and behaviour over 5 years have been reported. ${ }^{13}$ 
4 Logistic regression analyses of factors significantly influencing the intention to retire by 1048 medical practitioners in Australia

\begin{tabular}{|c|c|c|c|c|}
\hline & Intend to retire & No intention/don't know & Adjusted odds ratio $(95 \% \mathrm{Cl})$ & $P$ \\
\hline $\begin{array}{l}\text { Model 1: Whole sample } \\
P<0.001 ; \text { variance accounted, 9.5\% }\end{array}$ & $n=650$ & $n=398$ & & \\
\hline International medical graduate & $99(15.2 \%)$ & $106(26.6 \%)$ & $0.61(0.44-0.85)$ & 0.004 \\
\hline $\begin{array}{l}\text { RRI score: cognitive, emotional and motivational } \\
\text { resources, median (IQR) }\end{array}$ & $47(44-50)$ & $48(45-51)$ & $0.96(0.93-0.98)$ & 0.001 \\
\hline RRI score: financial resources, median (IQR) & $7(6-8)$ & $7(6-8)$ & $1.31(1.18-1.44)$ & $<0.001$ \\
\hline Work centrality, median (IQR) & $22(20-24)$ & $24(22-26)$ & $0.89(0.85-0.92)$ & $<0.001$ \\
\hline Anxiety about ageing, median (IQR) & $30(26-32)$ & $28(25-32)$ & $1.05(1.02-1.09)$ & $<0.001$ \\
\hline $\begin{array}{l}\text { Model 2: } 55-64 \text { years old } \\
P<0.001 ; \text { variance accounted, } 10.1 \%\end{array}$ & $n=335$ & $n=185$ & & \\
\hline International medical graduate & $33(9.9 \%)$ & $42(22.7 \%)$ & $0.47(0.28-0.80)$ & 0.005 \\
\hline RRI score: social, median (IQR) & $15(13-17)$ & $15(12-17)$ & $1.07(1.01-1.14)$ & 0.017 \\
\hline RRI score: financial resources, median (IQR) & $7(6-8)$ & $7(6-8)$ & $1.38(1.18-1.60)$ & $<0.001$ \\
\hline Work centrality, median (IQR) & $22(20-24)$ & $23(21-25)$ & $0.89(0.83-0.94)$ & $<0.001$ \\
\hline $\begin{array}{l}\text { Model 3: } 65 \text { years or older } \\
P<0.001 ; \text { variance accounted, } 10.2 \%\end{array}$ & $n=315$ & $n=213$ & & \\
\hline $\begin{array}{l}\text { RRI score: cognitive, emotional and motivational } \\
\text { resources, median (IQR) }\end{array}$ & $46(43-49)$ & $48(45-50)$ & $0.94(0.91-0.98)$ & 0.001 \\
\hline RRI score: financial resources, median (IQR) & $7(6-8)$ & $7(6-8)$ & $1.22(1.06-1.39)$ & 0.004 \\
\hline Work centrality, median (IQR) & $23(20-25)$ & $24(22-26)$ & $0.87(0.82-0.93)$ & $<0.001$ \\
\hline Anxiety about ageing, median (IQR) & $30(27-32)$ & $29(25-32)$ & $1.06(1.02-1.11)$ & 0.004 \\
\hline $\begin{array}{l}\text { Model 4: Men } \\
P<0.001 ; \text { variance accounted, } 8.8 \%\end{array}$ & $n=497$ & $n=310$ & & \\
\hline International medical graduate & $75(15.1 \%)$ & $82(26.5 \%)$ & $0.59(0.41-0.86)$ & 0.006 \\
\hline $\begin{array}{l}\text { RRI score: cognitive, emotional and motivational } \\
\text { resources, median (IQR) }\end{array}$ & $47(44-50)$ & $48(45-50)$ & $0.97(0.94-0.995)$ & 0.021 \\
\hline RRI score: financial resources, median (IQR) & $7(6-8)$ & $7(6-8)$ & $1.26(1.13-1.41)$ & $<0.001$ \\
\hline Work centrality, median (IQR) & $22(20-24)$ & $24(22-26)$ & $0.89(0.85-0.94)$ & $<0.001$ \\
\hline Anxiety about ageing, median (IQR) & $30(26-32)$ & $28(25-31)$ & $1.06(1.02-1.10)$ & 0.001 \\
\hline $\begin{array}{l}\text { Model 5: Women } \\
P<0.001 ; \text { variance accounted, } 13.8 \%\end{array}$ & $n=153$ & $n=88$ & & \\
\hline $\begin{array}{l}\text { RRI score: cognitive, emotional and motivational } \\
\text { resources, median (IQR) }\end{array}$ & $46(44-49)$ & $48(45-51)$ & $0.92(0.86-0.98)$ & 0.014 \\
\hline RRI score: financial resources, median (IQR) & $7(6-8)$ & $6(5-8)$ & $1.48(1.18-1.85)$ & 0.001 \\
\hline Work centrality, median (IQR) & $22(20-24)$ & $24(21-26)$ & $0.87(0.79-0.96)$ & 0.004 \\
\hline $\begin{array}{l}\text { Model 6: Medical specialties with more than } \\
50 \text { responses } \\
P<0.001 \text {; variance accounted, } 12.9 \%\end{array}$ & $n=462$ & $n=298$ & & \\
\hline International medical graduate & $74(16.0 \%)$ & $84(28.2 \%)$ & $0.67(0.45-0.99)$ & 0.044 \\
\hline General practitioner & $248(53.7 \%)$ & $191(64.1 \%)$ & $0.54(0.34-0.87)$ & 0.012 \\
\hline Psychiatrist & $28(6.1 \%)$ & $28(9.4 \%)$ & $0.40(0.20-0.79)$ & 0.009 \\
\hline $\begin{array}{l}\text { RRI score: cognitive, emotional and motivational } \\
\text { resources, median (IQR) }\end{array}$ & $47(44-50)$ & $48(45-50)$ & $0.95(0.92-0.98)$ & 0.001 \\
\hline RRI score: financial resources, median (IQR) & $7(6-8)$ & $7(6-8)$ & $1.31(1.17-1.48)$ & $<0.001$ \\
\hline Work centrality, median (IQR) & $22(20-25)$ & $24(22-26)$ & $0.87(0.82-0.92)$ & $<0.001$ \\
\hline Anxiety about ageing, median (IQR) & $30(27-32)$ & $29(25-32)$ & $1.07(1.03-1.11)$ & $<0.001$ \\
\hline
\end{tabular}

$\mathrm{RRI}=$ Retirement Resources Inventory. For all models, demographic variables were entered in a first block (eg, age groups, sex, international medical graduate, location of practice, specialty), before questionnaire data were entered in a second block (eg, RRI subscale, Self-Administered Comorbidity Questionnaire, work centrality, and Anxiety About Ageing scores). Note that it is possible for groups to have different rank sums that are statistically significant in non-parametric tests, but identical or nearly identical medians.

Our findings are relevant to developing education and support programs for assisting late career medical practitioners to transition to retirement. Retirement is potentially an emotional question for many doctors; learning about their colleagues' experiences may be helpful. Such programs should include general advice (including about financial and 
emotional resources), recognise work as part of self-identity, and target specific groups, such as IMGs and GPs. Programs should be provided within continuing professional development programs, and receive funding from the medical colleges.

Acknowledgements: Financial support for the study was provided by an unrestricted educational grant from Avant Mutual Group.
Competing interests: No relevant disclosures.

Editorial note: The MJA is published by AMPCo, but commercial decisions about the purchase and use of data from the AMPCo database by third parties are made by AMPCo without reference to the $M J A$.

Received 22 July 2016, accepted 17 Oct 2016.

(c) 2017 AMPCo Pty Ltd. Produced with Elsevier B.V. All rights reserved.
1 Australian Institute of Health and Welfare. Who are medical practitioners? Australia's medical workforce: medical professionals in Australia in 2015 [website]. http://www.aihw.gov.au/workforce/medical/who (accessed Apr 2016).

2 Australian Institute of Health and Welfare. Medical labour force 2004 (AlHW Cat. No. HWL 39; National Health Labour Force Series No. 38). Canberra: AlHW. 2006.

3 Draper B, Luscombe G, Winfield S. The Senior Psychiatrist Survey II: experience and psychiatric practice. Aust N Z J Psychiatry 1999; 33: 709-716.

4 Wijeratne C, Peisah C. Accepting the challenges of ageing and retirement in ourselves: the need for psychiatrists to adopt a consensus approach. Aust N Z J Psychiatry 2013; 47: 425-430.

5 Draper B, Winfield S, Luscombe G. The older psychiatrist and retirement. Int I Geriatr Psychiatry 1997; 12: 233-239.

6 Lee H, Drag L, Bieliauskas L, et al. Results from the Cognitive Changes and Retirement among Senior Surgeons Self-report Study. J Am Coll Surg 2009; 209: 668-671.

7 Martin S. "Freedom 55" closer to age 65 for physicians. CMAJ 2000; 163: 1499.

8 Topa G, Moriano J, Depolo M, et al. Antecedents and consequences of retirement planning and decision-making: a meta-analysis and model. J Voc Behav 2009; 75: 38-55.
9 Sadavoy J. The ageing physician. J Ger Psychiatry 1994; 27: 265-279.

10 Parboteeah K, Cullen J. Social institutions and work centrality: explorations beyond national culture. Org Sci 2003; 14: 137-148.

11 Wrzesniewski A, McCauley C, Rozin P, Schwartz B. Jobs, careers and callings: people's relations to their work. J Res Pers 1997; 31: 21-33.

12 Watkins R, Coates R, Ferroni P. Measurement of ageing anxiety in an elderly Australian population. Int J Aging Hum Dev 1998; 46: 319-332.

13 Solem P, Syse A, Furunes T, et al. To leave or not to leave: retirement intentions and retirement behaviour. Aging Soc 2016; 36: 259-281.

14 Leung C, Earl J. Retirement Resources Inventory: construction, factor structure and psychometric properties. J Vocat Behav 2012; 81: 171-182.

15 Sangha O, Stucki G, Liang M, et al. The SelfAdministered Comorbidity Questionnaire: a new method to assess comorbidity for clinical and health services research. Arthritis Rheum 2003; 49: 156-163.

16 Kessler R, Andrews G, Colpe L, et al. Short screening scales to monitor population prevalences and trends in non-specific psychological distress. Psychol Med 2002; 32: 959-976.

17 Lasher K, Faulkender P. Measurement of aging anxiety: development of the Anxiety about Aging Scale. Int J Aging Hum Dev 1993; 37: 247-259.
18 Lim G, Ng L. Early retirement and bridge employment intentions among older workers in Singapore. Asia Pacific J Manage 1997; 14: 185-210.

19 Australian Bureau of Statistics. 6238.0. Retirement and retirement intentions, Australia, July 2014 to June 2015. Mar 2016. http://www.abs.gov.au/ausstats/abs@.nsf/ mf/6238.0 (accessed July 2016).

20 Peisah C, Gautam M. Goldstein M. Medical masters: a pilot study of adaptive ageing in physicians. Australas $J$ Ageing 2009; 28: 134-138.

21 Wong J, Earl J. Towards an integrated model of individual, psychosocial, and organizational predictors of retirement adjustment. J Voc Behav 2009; 75: 1-13.

22 Australian Bureau of Statistics. 6361.0. Employment arrangements, retirement and superannuation, Australia, April to July 2007 (re-issue). June 2009. http://www.abs.gov.au/ausstats/abs@.nsf/mf/6361. 0.55.004 (accessed July 2016).

23 Waxman B. The aging psychiatrist: lessons from our colleagues in surgery and anaesthesia. Australas Psychiatry 2016; 24: 155-156.

24 Joyce C, Schurer S, Scott A, et al. Australian doctors' satisfaction with their work: results from the MABEL longitudinal survey of doctors. Med J Aust 2011; 194: 30-33. https://www.mja.com.au/journal/2011/194/1/ australian-doctors-satisfaction-their-work-resultsmabel-longitudinal-survey 